\title{
OLIVINE AS A REFRACTORY
}

\author{
By R. A. Heindl and W. L. Pendergast
}

\section{ABSTRACT}

Olivines representing three different deposits in North Carolina and one each in California, British Columbia, and Russia were tested to determine the possibilities of the material as a refractory. The chemical analyses were made on the raw materials, and linear thermal expansions, specific gravities, pyrometric cone equivalents, and petrographic analyses on both the raw and heated materials. The results show that olivine from North Carolina apparently has the necessary properties demanded of a high-grade special refractory and that it might be used in industrial processes where possible contamination by iron is of no consideration.

\section{CONTENTS}

I. Introduction

II. Materials _._.

III. Methods of testing and results $\ldots$

1. Chemical analyses............. 216

2. Linear thermal expansion

3. True 'specific gravity

4. Pyrometric cone equivalents (softening temperatures) _.... 218

5. Linear shrinkage _......... 219

6. Petrographic analyses

IV. Discussion of results and preparation of brick

V. Summary and conclusions

\section{INTRODUCTION}

Olivine is a greenish, transparent to translucent mineral, usually occurring in granular aggregates or as small disseminated, glassy grains. ${ }^{1}$ It is a silicate of iron and magnesium, $2(\mathrm{Mg}, \mathrm{Fe}) \mathrm{O} . \mathrm{SiO}_{2}$, and as found in nature is a solid solution of forsterite $\left(\mathrm{Mg}_{2} \mathrm{SiO}_{4}\right)$ and fayalite $\left(\mathrm{Fe}_{2} \mathrm{SiO}_{4}\right)$.

Large quantities of this material are available in North Carolina and some speculation has arisen relative to its suitability as a special refractory. Since olivine is quite rich in magnesium, and if it should prove to be basic or semibasic in character, its use in certain metallurgical operations where magnesite is employed at present may be advantageous. This applies especially to its use in industries along the eastern seaboard, since magnesite must be shipped from either the West Coast or imported. Very little information is available relative to the properties of this material; consequently the desirability and necessity of additional information led to a short study of those properties which might aid in its classification.

1 Raymond B. Ladoo, Nonmetallic Minerals, p. 417 (1925); also Winchell, Elements of Optical Mineral ogy, pt. II, p. 166 . 


\section{MATERIALS}

Small samples of five olivines were secured from the National Museum and a sixth from the United States Bureau of Mines. The laboratory key letters and the approximate source of the material as furnished by the Museum are given in table 1. A sample of calcined magnesite secured from a manufacturer of refractory bricks was included for comparative purposes.

\section{METHODS OF TESTING AND RESULTS}

\section{CHEMICAL ANALYSES}

The chemical compositions of the several olivines are given in table 1. It may be noted that the content of magnesium oxide ranges from about 39 to 49 percent and is approximately one half that found in commercial magnesite brick. The lime content of the North Carolina materials is very small. The iron content of sample " $\mathrm{F} " 2$ and the lime content of sample " $D$ " is very high in comparison with that found in the remainder of the samples. The range in silica

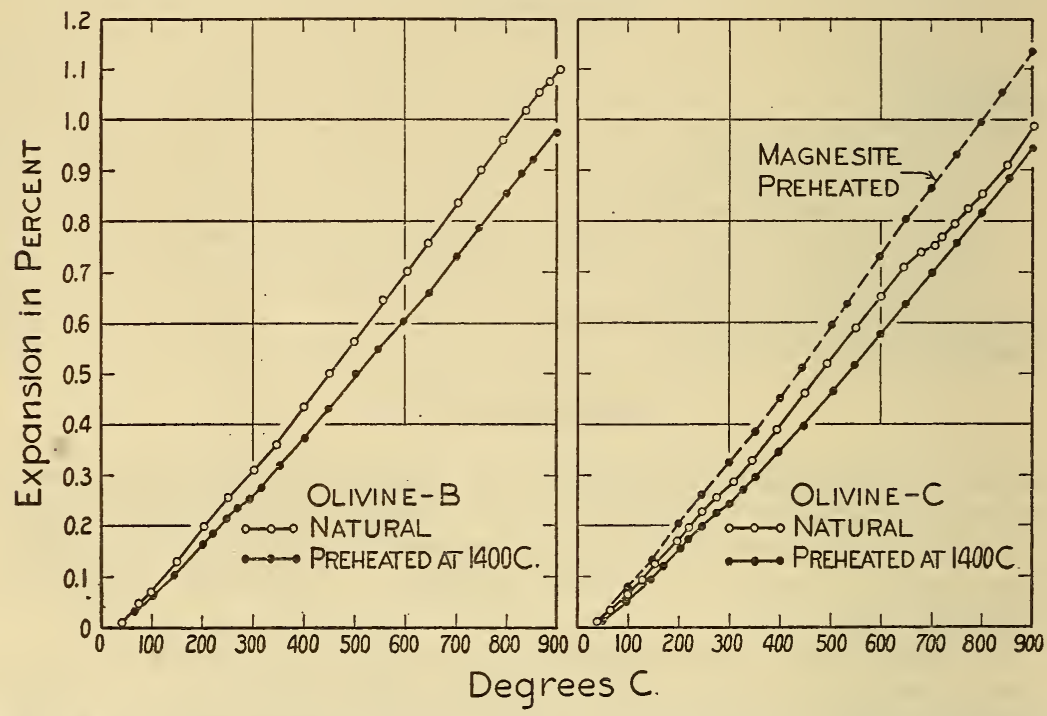

FIGURE 1.-Linear thermal expansion of (1) untreated or raw olivine, (2) olivine after having been heated at $1,400 \quad C$, (3) calcined magnesite after heating at $1,400 \mathrm{C}$.

content (40 to 45 percent) is rather narrow, approximating 5 percent from the lowest to the highest values.

\section{LINEAR THERMAL EXPANSION}

The linear thermal expansions of the olivines were measured from room temperature to $900 \mathrm{C}$ with the interferometer. ${ }^{3}$ The furnace was heated at an average rate of approximately $4 \mathrm{C}$ per minute.

\footnotetext{
2 This material is also known as "Glinkite." A System of Mineralogy, by E. S. Dana, p. 453 (1911 edition).

3 C. G. Peters and C. H. Cragoe, B.S. Scientific Paper No. 393, and G. E. Merritt, B.S. Research Paper No. 515.
} 


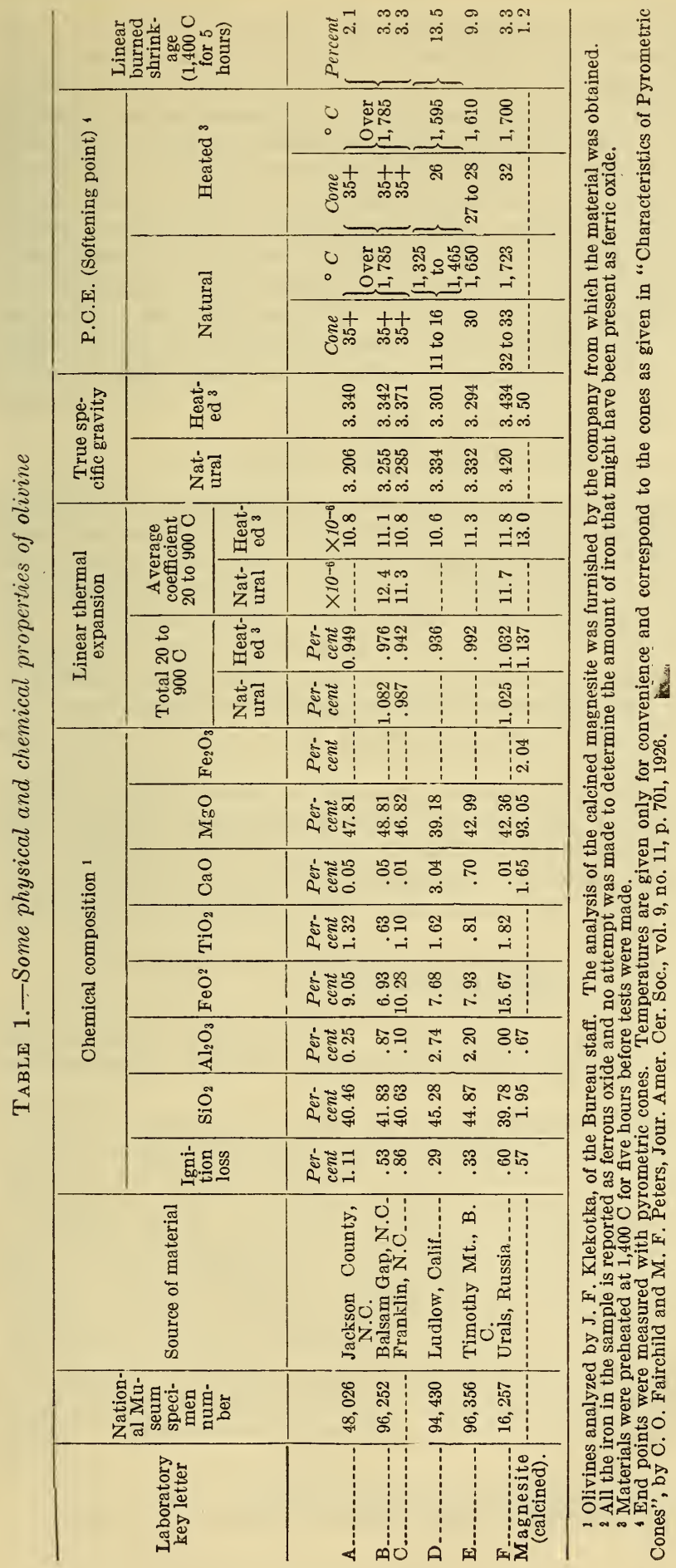


The data obtained are given in table 1 and typical curves are given in figure 1. The average coefficient of expansion per degree centigrade between 20 and $900 \mathrm{C}$ ranged from 0.0000106 to 0.0000118 . The expansion of the natural material was measured on samples B, C, and F only. Rates of expansion were fairly regular except for slight irregularities between 200 and $300 \mathrm{C}$ and again between 650 and $700 \mathrm{C}$ approximately. These irregularities were more pronounced in samples $\mathrm{C}$ and $\mathrm{F}$ than in $\mathrm{B}$. After heating at $1,400 \mathrm{C}$ for 5 hours, the total expansion at $900 \mathrm{C}$ for materials $B$ and $C$ was somewhat lower and the irregularity in the curve between 200 and $300 \mathrm{C}$ was still noticeable, but no irregularity was evident in the rate of expansion above $300 \mathrm{C}$. The data in table 1 and the curve in figure 1 show that the linear thermal expansion of magnesite brick after having been heated at 1,400 $\mathrm{C}$ is somewhat greater than that of the olivines.

\section{TRUE SPECIFIC GRAVITY}

The specific gravities of the olivines were determined according to the A.S.T.M. standard method for specific gravity of pigments, ${ }^{4}$ serial designation $D$ 153-27, promulgated by the American Society for Testing Materials. Values obtained both on the raw materials and after heating them to $1,400 \mathrm{C}$ for 5 hours are given in table 1 . The specific gravity of calcined magnesite is included for comparative purposes. The values represent the average of three determinations (except sample $C$, raw, only two determinations) and in no case was there a greater variation from the average than \pm 0.005 . The range was from 3.206 to 3.436 .

The specific gravity of samples $D$ and $E$ is higher when tested in the natural state than when tested after heating at 1,400 C. The other samples show higher values after heating when compared with the same material not heated. Both $D$ and $E$ have a high lime content and $D$ apparently was fused after the preheating at 1,400 C.

\section{PYROMETRIC CONE EQUIVALENTS (SOFTENING TEMPERATURES)}

The pyrometric cone equivalents were determined according to the A.S.T.M. standard method, serial designation $C 24-31,{ }^{5}$ and are given in table 1 .

The P.C.E. of the three olivines from North Carolina was above 35 (under the conditions of the test cone 35 is approximately $1,785 \mathrm{C}$ ), the highest temperature conveniently obtainable with the furnace used, and showed no difference whether tested in the natural state or preheated at $1,400 \mathrm{C}$ for 5 hours. The values of the others ranged from cones 11 to 33 . The natural material and the same material preheated to $1,400 \mathrm{C}$ did not give duplicate values, sample $D$ being appreciably higher after preheating and $E$ appreciably lower. Sample $F$ gave only slightly different results with the natural and preheated specimens, but showed a very much higher shrinkage than the other samples during these tests. It was estimated that the cones after completion of the tests were only about one third their original size.

${ }^{4}$ American Society for Testing Materials Book of Standards for 1930, pt. II, p. 345.

- Described in American Society for Testing Materials Book of Standards for 1930, pt. II, p. 210. 


\section{LINEAR SHRINKAGE}

The values for linear shrinkage of the olivines during heating at $1,400 \mathrm{C}$ for 5 hours and given in table 1 should not be considered as exact, since the measurements were made on rather small specimens. Each of the results represents the average values of not less than three specimens. For purposes, however, of comparing the relative amount of shrinkage of the several samples during heating the values should be satisfactory. The olivines containing the highest percentages of calcium oxide show by far the greatest shrinkage. The shrinkage of the commercial magnesite appears low because the tests were made on calcined material, whereas the olivine specimens were made with the natural or untreated materials.

\section{PETROGRAPHIC ANALYSES ${ }^{6}$}

Petrographic analyses were made on the several olivines before and after the various heat treatments in order to obtain information relative to the effect of the various heat treatments on their composition. From the petrographic examination an estimation may be made of the relative quantities of forsterite and fayalite present in each of the samples. The results of the analyses follow:

Sample $A$. Webster, N.C.

Natural state.-Largely olivine. Impurity (approximately 15 percent) is largely serpentine. Optical properties of olivine indicate composition $^{7}$ to be 96 percent forsterite and 4 percent fayalite approximately.

Heated at 1,400 C.-Composed of olivine (pure or nearly pure forsterite) with minute dark colored inclusions along cleavage planes. The inclusions may be magnesio-ferrite, magnetite and hematite.

Heated to cone 32 (approximately 1,700 C).-Not greatly different from preceding sample.)

Sample B. Balsam Gap, N.C.

Natural state.-Largely olivine and less than 10 percent serpentine. Optical properties indicate about 95 percent forsterite and 5 percent fayalite approximately.

Heated at 1,400 C.-Very similar to sample $A$ after the same heat treatment.

Heated at cone $34(1,760 \mathrm{C})$.-Not greatly different from preceding sample except material is slightly magnetic.

Sample $C$. Franklin, N.C.

Natural state.-Largely olivine (92 percent forsterite and 8 percent fayalite approximately). Impurities consist of $(a)$ approximately 5 percent serpentine, $(b)$ approximately 5 percent of an unidentified material which may be magnetite, (c) very small percentages of a pyroxene and basic feldspar.

\{Heated to $1,400 \mathrm{C}$.

Heated to cone $33(1,745 \mathrm{C})$.--Not greatly different from samples $A$ and $B$ after heating.

Sample $D$. Ludlow, Calif.

Natural state.-Largely olivine (90 percent forsterite and 10 percent fayalite). Impurities totaling approximately 10 percent consist of

7 See Winchell, Elements of Optical Mineralogy, pt. II, p. 168. 
small amounts of (a) a monoclinic pyroxene, $(b)$ isotropic crystals of what may be a spinel, $(c)$ serpentine.

Heated at 1,400 C.-Olivine (pure or nearly pure forsterite) with abundant inclusions of $(a)$ opaque particles (probably magnetite), (b) low index glass, (c) particles of what may be magnesio-ferrite. The material is slightly magnetic.

Heated to cone $16(1,450 C)$.- - Not greatly different from preceding specimen except material was nonmagnetic.

Sample E. Timothy Mountain, B.C.

Natural state.-Largely olivine (approximately 92 percent forsterite and 8 percent fayalite). Impurities consist of small amounts of $(a)$ crystals of what may be a spinel, (b) opaque particles which may be hercynite.

Heated at 1,400 C.-Predominantly olivine. Contains small amounts of (1) high index particles of what is probably magnesioferrite, (2) opaque particles of what may be magnetite, (3) clinoenstatite, (4) glass. The material is slightly magnetic.

Heated at cone $30(1,650 \mathrm{C})$. - Not greatly different from preceding specimens.

Sample F. Urals, Russia

Natural state.-Largely olivine (80 percent forsterite and 20 percent fayalite approximately). Impurities are present in small amounts as (1) serpentine and (2) opaque particles of an unidentified material.

SHeated at 1,400 C.

Heated at cone $32(1,700 \mathrm{C})$.--Olivine (pure or nearly pure forsterite) predominates. Impurities present were not definitely identified but indications point to presence of (1) magnetite, (2) hematite, (3) magnesio-ferrite, (4) glass. Crushed material is magnetic.

The principal result of heating the olivines to $1,400 \mathrm{C}$ or higher was the apparent removal of the fayalite from the solid solution series (and its subsequent decomposition), leaving the olivines composed almost wholly of forsterite.

\section{DISCUSSION OF RESULTS AND PREPARATION OF BRICK}

The refractoriness to heat of the olivines from North Carolina was such as to warrant the conclusion that they should prove suitable for use in certain industrial processes where a so-called special refractory material is desirable. Although the thermal expansion is high, it is somewhat lower than that of calcined magnesite. Burning shrinkage is very small compared with that of other refractory materials, consequently preheating or calcining of the material is not necessary before being manufactured into brick. The disappearance of the fayalite during heating apparently has no detrimental effect on the structure of material.

In order to determine the feasibility of preparing brick from olivine, a sample of run-of-mine material from North Carolina was crushed and sieved. The material used had the following sieve analysis: Through no. 6 sieve and retained on no. 14, 371/2 percent; through no. 14 sieve and retained on no. $40,37 \frac{1}{2}$ percent; through no. 40 , 25 percent. A solution of gum tragacanth was added as the binder and the material was pressed into standard-size bricks in a laboratory 
hand press, dried, and heated at approximately 1,425 C for five hours. The finished brick were well bonded and had a statisfactory appearance after the heat treatment. The following results of tests representing the average on three specimens are given so that some idea may be formed as to certain physical properties of the burned bricks: Modulus of rupture, $325 \mathrm{lb} / \mathrm{in}^{2}$; compressive strength, 5,250 lb/in. ${ }^{2}$; absorption (by weight, 5 hour boiling), 12 percent, shrinkage (firing), 1.1 percent.

Crucibles were made by coring sections of the brick and filling them with a mixture of equal parts by weight of olivine, ground to pass a no. 100 sieve, and (1) flint, (2) ground magnesite brick, (3) low fusing portland cement, (4) alumina. Crucibles were made from a commercial magnesite brick and filled with similar mixtures, but the olivine in each case was replaced by magnesite. In addition, a crucible made from a silica brick contained a mixture of ground silica brick and olivine. The crucibles and materials were heated to and held at approximately $1,575 \mathrm{C}$ for $1 \frac{1}{2}$ hours. The results of these slag tests, which are given in table 2 , should be considered only as indicative and not as conclusive evidence of what might be expected because of the very limited amount of work done.

TABLE 2.-Results of some slag tests with olivine and magnesite bricks ${ }^{1}$

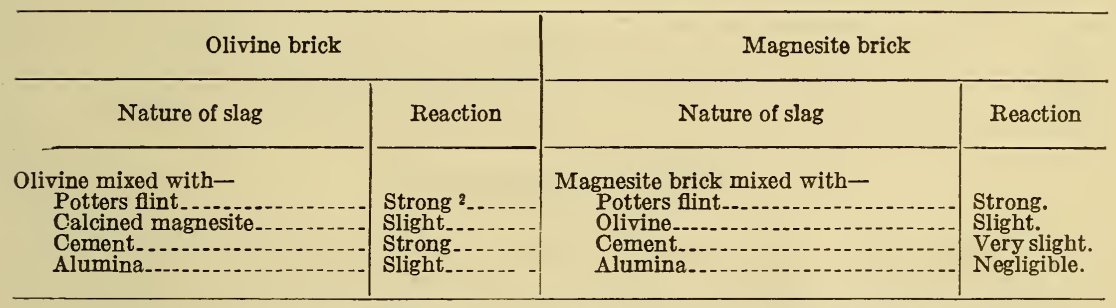

1 The mixture of olivine and finely ground silica brick on a silica brick showed very slight reaction.

2 The crucible was directly in the path of the flame and the temperature to which it was subjected was much higher than that of the other crucibles. This was indicated by the fused and bloated appearance of the crucible and any result obtained would not be considered exactly comparable.

\section{SUMMARY AND CONCLUSIONS}

Samples of six olivines representing different deposits were studied in order to determine the suitability of this type of material for refractory purposes. The chemical analyses were obtained on the raw material, the linear thermal expansion, pyrometric cone equivalents (softening points), specific gravities, and petrographic analyses on both the raw material and material heated at 1,400 C. The following results were noted:

1. The chemical analyses showed the silica to range from 40 to 45 percent approximately, magnesium oxide 40 to 49 percent approximately, iron as ferrious oxide 7 to 15 percent approximately, and lesser amounts of alumina, calcium, and titanium.

2. The rate of thermal expansion was fairly regular from room temperature to $900 \mathrm{C}$ except for slight irregularities between 200 and $300 \mathrm{C}$, and again between 650 and $700 \mathrm{C}$, approximately. These irregularities were less evident in the heated material than in the raw. The total expansion from 20 to $900 \mathrm{C}$ ranged from 0.942 to 1.082 percent and is somewhat lower than that of magnesite. 
3. The true specific gravity ranged between 3.206 and 3.420 for the raw material and between 3.294 and 3.434 for the material heated at $1,400 \mathrm{C}$. The specific gravity of the materials low in calcium oxide was decreased by heating.

The P.C.E. (softening point) of the raw ore ranged from 30 to above 35 , except the material high in calcium oxide which varied from 11 to 16 . The P.C.E. of the raw material was not necessarily the same as that obtained on the material after heating at 1,400 C.

4. The olivines from North Carolina were more refractory than those from the other sources..$^{8}$

5. The petrographic examination indicated the material to be essentially olivine. The percentages of forsterite and fayalite varied quite appreciably with the respective olivines.

The results indicated that the material from North Carolina was sufficiently refractory to heat and some types of slag to warrant its use as a special refractory. Bricks were easily made from run-ofmine material and proved satisfactory in the few physical tests to which they were subjected.

Washington, October 28, 1933.

${ }_{8}$ U.S. Patent 1,926,094 has some bearing on the use of olivine in refractories and an anonymous article appearing in British Clayworker, 41 (484) 168 (1932), refers to certain magnesium silicates and patented processes incidental to their use or manufacture. 